
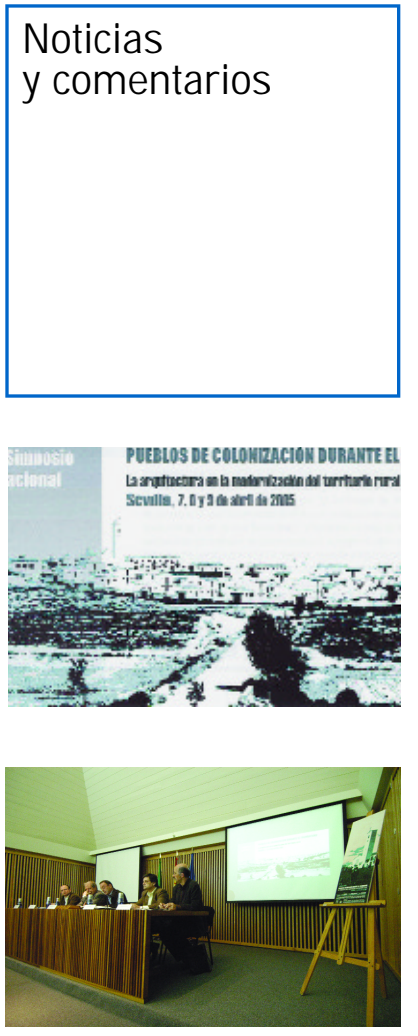

Jornada de inauguración del simposio. Imagen: Eugenio Fernández

\title{
El I Simposio Nacional "Poblados de Colonización durante el franquismo" deriva en un foro de encuentro permanente
}

Durante los días 7, 8 y 9 de abril se celebró en la sede del Instituto Andaluz de Patrimonio Histórico en Sevilla el I Simposio Nacional "Pueblos de Colonización durante el franquismo: la arquitectura en la modernización del territorio rural". El encuentro fue organizado por el IAPH y la Universidad de Sevilla con el fin de profundizar en el conocimiento de dichos pueblos y difundir iniciativas encaminadas a promover su desarrollo.

Tras la presentación institucional a cargo del director del IAPH, Román Fernández-Baca, el simposio fue abierto por Victor Pérez Escolano con una ponencia introductoria sobre la acción del Instituto Nacional de Colonización (INC) a lo largo de más de treinta años y sus inmediatos antecedentes republicanos. Seguidamente, Donatella Calabi hizo un balance internacional de las distintas experiencias de colonización durante el siglo XX como marco previo donde encuadrar las actuaciones del INC. Asimismo, Juan Francisco Ojeda Rivera desarrolló una ponencia sobre distintos tipos de colonización desde la perspectiva geográfica de análisis paisajístico.

Esta primera jornada del encuentro también contó con la exposición de comunicaciones que abordaban y completaban algunos de los temas esbozados durante el día: los precedentes de la colonización, la estructura administrativa del INC, los paralelismos constructivos entre INC y Regiones Devastadas y un análisis de la incidencia sobre el territorio y las vías pecuarias de la colonización franquista.

La jornada se completó con la presentación por parte de Cristóbal Gómez Benito del Centro de Interpretación de la Colonización de Sodeto (Huesca), la proyección del documental "Pueblos de Colonización" de José Antonio Parejo y una mesa redonda presidida por José Luis Monclús en la que, además de los ponentes de la jornada, participaron Cristóbal Gómez Benito y Ángel Barbero Martín, Subdirector General de Regadíos y Economía del Agua.

La segunda jornada se inició con una visita a los pueblos de El Priorato (arquitecto Antonio Fernández Alba), Setefilla (Fernando de Terán) y Esquivel (Alejandro de la Sota). En la visita se pudo comprobar tanto la diversidad de enfoques apuntada el día anterior como la necesidad de una estrategia de intervención y protección patrimonial, urgente en el caso de Esquivel pero necesaria a todos ellos. La sesión de la tarde estuvo encabezada por la ponencia de Fernando de Terán, que sirvió para ilustrar sobre las influen- cias y métodos de diseño de los pueblos seguidos por los autores de los mismos.

Las comunicaciones del día versaron sobre ejemplos concretos de trazados: la zona de secano de Castilla-La Mancha, el proyecto no realizado de Rafael Aburto para La Puebla de Don Rodrigo y la colonización dispersa en Galicia. Asimismo, Gonzalo Acosta presentó el libro "El canal de los presos" y otras iniciativas investigadoras y divulgativas sobre la memoria de la colonización, como el proyecto para un centro de interpretación de los trabajos forzados en Sevilla.

La jornada se cerró con una mesa redonda presidida por Carlos Sambricio y compuesta por José Antonio Corrales, Fernando de Terán y José Luis Sánchez. En este emocionante encuentro, la rara lucidez que a veces tienen los que han sido protagonistas de una época contradictoria y difícil sirvió para evocar la figura de José Luis Fernández del Amo y a través suya la de toda una generación comprometida en la modernización de España.

La última jornada del encuentro fue abierta por la ponencia de José Luis Oyón, que expuso su visión del estado de conocimiento actual y las vías por explorar por futuras investigaciones. Las comunicaciones atendieron en esta sesión a enfoques necesarios para profundizar en algunos de los aspectos apuntados por el encuentro: un balance general de la colonización en la provincia de Jaén, los artistas y las iglesias de Fernández del Amo para el INC y estrategias de estudio y observación para la integración de los pueblos en el paisaje. Julián Oslé expuso el proyecto de Centro de Interpretación de Guadalcacín.

Dentro de las conclusiones del Simposio, los participantes destacaron la necesidad de profundizar en el conocimiento y contacto de las distintas iniciativas investigadoras y de recuperación patrimonial. Para ello, se ha propuesto la creación de un foro de encuentro permanente, cuyo soporte podría ser internet y en el que se prolonguen y enriquezcan los contactos establecidos durante los días del encuentro.

Manuel Calzada Pérez

Organización del Simposio 